\title{
Chondroitinase ABC Promotes Recovery of Adaptive Limb Movements and Enhances Axonal Growth Caudal to a Spinal Hemisection
}

\author{
Stephanie C. Jefferson, ${ }^{1,2,3}$ Nicole J. Tester, ${ }^{1,2,3,4}$ and Dena R. Howland ${ }^{1,2,3}$ \\ ${ }^{1}$ Brain Rehabilitation and Research Center, Malcom Randall VA Medical Center, Gainesville, North Florida/South Georgia Veterans Health System, Florida \\ 32608, ${ }^{2}$ Department of Neuroscience, College of Medicine, University of Florida, Gainesville, Florida 32610, ${ }^{3}$ McKnight Brain Institute, University of \\ Florida, Gainesville, Florida 32611, and ${ }^{4}$ Department of Physical Therapy, College of Public Health and Health Professions, University of Florida, \\ Gainesville, Florida 32610
}

A number of studies have shown that chondroitinase $\mathrm{ABC}$ (Ch'ase $\mathrm{ABC}$ ) digestion of inhibitory chondroitin sulfate glycosaminoglycans significantly enhances axonal growth and recovery in rodents following spinal cord injury (SCI). Further, our group has shown improved recovery following SCI in the larger cat model. The purpose of the current study was to determine whether intraspinal delivery of Ch'ase $\mathrm{ABC}$, following T10 hemisections in adult cats, enhances adaptive movement features during a skilled locomotor task and/or promotes plasticity of spinal and supraspinal circuitry. Here, we show that Ch'ase ABC enhanced crossing of a peg walkway post-SCI and significantly improved ipsilateral hindlimb trajectories and integration into a functional forelimb-hindlimb coordination pattern. Recovery of these complex movements was associated with significant increases in neurofilament immunoreactivity immediately below the SCI in the ipsilateral white ( $p=0.033)$ and contralateral gray matter $(p=0.003)$. Further, the rubrospinal tract is critical in the normal cat during skilled movements that require accurate paw placements and trajectories like those seen during peg walkway crossing. Rubrospinal connections were assessed following Fluoro-Gold injections, caudal to the hemisection. Significantly more retrogradely labeled right (axotomized) red nucleus (RN) neurons were seen in Ch'ase ABC-treated (23\%) compared with control-treated cats $(8 \% ; p=0.032)$ indicating that a larger number of RN neurons in Ch'ase ABC-treated cats had axons below the lesion level. Thus, following SCI, Ch'ase ABC may facilitate axonal growth at the spinal level, enhance adaptive features of locomotion, and affect plasticity of rubrospinal circuitry known to support adaptive behaviors in the normal cat.

\section{Introduction}

Chondroitinase $\mathrm{ABC}$ (Ch'ase $\mathrm{ABC}$ ) has been used experimentally to cleave inhibitory chondroitin sulfate glycosaminoglycans (CS GAGs) (for review, see Busch and Silver, 2007; Crespo et al., 2007; Kwok et al., 2008; Bradbury and Carter, 2011). Delivery of this bacterial enzyme in rodents following several models of spinal cord injury (SCI) has been associated with behavioral recovery as well as enhancement of axonal growth. Work from our group shows that Ch'ase ABC also affects motor function following SCI in the cat (Tester and Howland, 2008). Benefits of testing in the cat include its remarkable locomotor capacity, well characterized circuitry associated with different features of locomotion (Arm-

Received Aug. 23, 2010; revised Jan. 17, 2011; accepted Feb. 16, 2011.

This research was supported by National Institutes of Health-National Institute of Neurological Disorders and Stroke Grants 5R01NS050699 and T32 HD043730, the Daniel Heumann Fund, the Department of Veterans Affairs, and the New York Spinal Cord Research Board. We thank graduate students Adele Blum and Sarah Mondello, Wilbur O'Steen (laboratory manager), and multiple technicians in the Howland laboratory who assisted with behavioral data collection and surgeries. In addition, we thank Dr. Brian Howland for his invaluable input with statistical analyses, Dr. Robert Linhardt for his expertise and assistance with enzyme activity tests, and the MBF support staff for their expert guidance on the choice and use of the stereological assessments used in this work. The contents of this article do not represent the views of the Department of Veterans Affairs or the United States government.

Correspondence should be addressed to Dena R. Howland, Department of Neuroscience and McKnight Brain Institute, University of Florida, 100 Newell Drive, Gainesville, FL 32611. E-mail: howland@mbi.ufl.edu.

DOI:10.1523/JNEUROSCI.4459-10.2011

Copyright $\odot 2011$ the authors $\quad 0270-6474 / 11 / 315710-11 \$ 15.00 / 0$ strong, 1986, 1988; Armstrong and Marple-Horvat, 1996; Drew et al., 1996, 2002; Whelan, 1996; Mori et al., 1998; Barbeau et al., 1999; Rossignol et al., 1999, 2001, 2002; Barrière et al., 2008), large spinal cord, CS GAG sulfation patterns (Tester and Howland, 2008), and use as a platform for translation (Braughler et al., 1987; Hodgson et al., 1994; Behrman and Harkema, 2000; de Leon et al., 2001).

Our prior work showed that intralimb movement patterns during basic locomotion on the treadmill and crossing a simple runway were more similar to pre-injury in Ch'ase ABC-treated cats than controls. Of particular interest, intraspinal delivery of Ch'ase ABC across 1 month following a thoracic hemisection enhanced ipsilateral hindlimb use during skilled locomotor tasks (Tester and Howland, 2008). Although not tested anatomically, this recovery suggested involvement of the rubrospinal system. In the normal cat, the rubrospinal tract (RST) contributes to coordinated, multiarticular movements (Gibson et al., 1985; Mewes and Cheney, 1994), gait adaptations, and interlimb coordination (Widajewicz et al., 1994; Lavoie and Drew, 2002), which are all important during skilled forms of locomotion. There also is precedent in the rat to suggest that this system may respond favorably to Ch'ase ABC treatment (Yick et al., 2004).

The current study focuses on the effects of thoracic hemisection and intraspinal Ch'ase $\mathrm{ABC}$ delivery on precise limb targeting and interlimb coordination during a peg walkway task. The 
specific movement patterns of the ipsilateral hindlimb, including how it is integrated using angular kinematics, scoring of limb placement, and footfall and support patterns are characterized until 16-20 weeks post-injury. Further, phosphorylated neurofilament heavy chain (pNF-H) immunoreactivity is used to assess general axonal growth, and retrograde tract tracing with FluoroGold (FG) to assess red nucleus (RN) contributions below the lesion. Significant behavioral and anatomical differences are found between Ch'ase ABC-treated cats and controls. Movement patterns of the Ch'ase $\mathrm{ABC}$-treated cats are predictable and similar across animals as well as distinctly different from pre-injury and recovery pattern of controls. Significant differences also are found with regards to axonal growth caudal to the lesion. pNF-H immunoreactivity is greater in the ipsilateral white and contralateral gray matter in Ch'ase $\mathrm{ABC}$-treated cats compared with controls. Further, an average of $23 \%$ of the hindlimb projecting neurons in the axotomized red nucleus have axons caudal to the lesion in Ch'ase $\mathrm{ABC}$-treated cats compared with $8 \%$ in controls.

\section{Materials and Methods}

Animals. Twenty-two adult female, spayed cats $(6-8 \mathrm{lbs})$, purchased from specific-pathogen-free vendors (Liberty Laboratories, Harlan Laboratories) and housed in the Association for Assessment and Accreditation of Laboratory Animal Care-accredited animal facility in the McKnight Brain Institute, were used. Animal procedures were conducted in accordance with the National Institutes of Health guidelines for the care and use of experimental animals and were approved by the University of Florida's and the Malcom Randall VA Medical Center's Institutional Animal Care and Use Committees.

Surgical procedures. Spinal T9/10 hemisections were performed as previously described (Tester and Howland, 2008) and briefly are presented here. The individual performing the spinal lesions was blinded to the treatment group assignments of the cats. Penicillin G procaine $(40,000 \mathrm{U} / \mathrm{kg}$ body weight, i.m. $)$ was given the day before, the day of, and the day after surgery. Before all surgeries, cats received $0.1 \mathrm{cc}$ atropine sulfate $(0.04-0.06 \mathrm{mg} / \mathrm{kg}$, s.c.) and $0.1 \mathrm{cc}$ acepromazine $(0.4-0.5 \mathrm{mg} / \mathrm{kg}$, s.c.). Cats were anesthetized and maintained with isoflurane (1-3.5\%) and intravenous fluids (lactated Ringers, $10 \mathrm{ml} / \mathrm{kg} / \mathrm{h}$ ). Respiratory and heart rate, expired $\mathrm{CO}_{2}, \mathrm{SPO}_{2}$, body temperature, and general plane of anesthesia were monitored closely.

A left lateral hemisection was made at spinal T9 or T10 using iridectomy scissors. Light suction with a pulled glass pipette was used if necessary to lift any fibers adhered to the dura to allow cutting without compromising dural integrity. Thrombin and Gelfoam were used to stop bleeding. Subcutaneous micro-implantable infusion ports (Harvard Apparatus) were sutured to muscle lateral to the vertebral column. Port tubing was held in place by suturing it to the muscle at several points until it reached dorsal midline. VetBond (Webster Veterinary Supply) was used to secure it to the lamina caudal to the laminectomy. The end of the port tubing was secured in the lesion cavity by suturing the dura $(8-0$ Prolene). Before final dural suturing, the port reservoir and tubing $(\sim 5$ $\mu \mathrm{l}$ total volume) were filled with either protease-free Ch'ase ABC (1 U/200 $\mu$ l Tris-HCl or saline, $\mathrm{pH} 7.8$; Seikagaku Corp.) or vehicle control (Tris-HCl, pH 7.8). Durafilm (Codman-Shurtleff) and Gelfoam (Pfizer) were placed over the dural sutures and the muscle and skin sutured. Anesthesia was terminated, cats were extubated, and then placed in temperature controlled recovery chambers (ThermoCare). Buprenorphine $(0.01 \mathrm{mg} / \mathrm{kg}$, s.c. $)$ was administered three times a day for $48 \mathrm{~h}$.

Procedures used to maintain the general health of the cats were similar to those described in our previous studies (Howland et al., 1995a,b). Once body temperature stabilized to a minimum of $100^{\circ} \mathrm{F}$, cats returned to their home cages with 5- to 7-inch-thick egg crate foam cushions covering the entire cage floor to prevent peripheral nerve compression, pressure sores, and skin breakdown. None of the animals developed any of these complications. Bladders were expressed manually using Crede's method until voluntary voiding recovered (typically 1-4 d). Animal health was continuously monitored throughout the study, including maintenance of food intake and body weight. Body weights were maintained within $10 \%$ of preoperative weight.

Treatment administration. Ten cats were treated with Ch'ase $\mathrm{ABC}$ and 12 cats were controls. Of the controls, 8 received hemisections-only (no port; 2 were non-behavior cats) and 4 received vehicle.

Commercial Ch'ase ABC may not retain its stability at body temperature for extended periods (Tester et al., 2007), therefore $\sim 50 \mu \mathrm{l}$ of protease-free Ch'ase ABC (1 U/200 $\mu \mathrm{l})$, or vehicle were injected every other day for 1 month. The concentration delivered was identical to that in our previous study (Tester and Howland, 2008). The volume is greater than that used in rodent studies (Bradbury et al., 2002) due to the larger size of the cat spinal cord. For treatment administration, the cats were anesthetized (1-3\% isoflurane and $1.5 \mathrm{~L}$ of $\mathrm{O}_{2}$ ) for $15 \mathrm{~min}$ while the Ch' ase $\mathrm{ABC}$ or vehicle was delivered $(0.14 \mathrm{~L} / \mathrm{min})$ using a microinjection syringe pump (Harvard Apparatus).

Behavioral training and quantitative locomotor assessments. Cats were trained daily ( 5 times/week) on a variety of locomotor tasks as described in our previous work (Tester and Howland, 2008). These tasks included treadmill stepping and crossing of a basic runway, ladder, narrow beam, and peg walkway. For the purposes of this paper only the results of the skilled peg walkway task are presented. This task was chosen for analyses because it requires a high level of balance and limb trajectory adaptations and is the most difficult to perform. The horizontal peg walkway was $4.5 \mathrm{~m}$ in length. Alternating pegs on the right and left side of the peg walkway, 12 pegs on the right side and 11 on the left side, were spaced evenly along the length of the board at $20 \mathrm{~cm}$ intervals. The width between the right and left pegs was $15 \mathrm{~cm}$. The surface of each peg was 3.8 $\mathrm{cm}^{2}$ and the height $30.5 \mathrm{~cm}$. Crossing of the peg walkway was conditioned to a food reward, and when performance was consistent, baseline data were collected pre-injury. All cats then received a left T9/10 hemisection. Twenty cats were divided equally between the control $(n=10)$ and Ch'ase ABC-treated groups $(n=10)$. Basic locomotor training was reinitiated within $24 \mathrm{~h}$ and peg walkway crossing after the first postoperative week. Manual trainer assistance was given as necessary to assist with weight support, postural control, and paw placement during peg walkway crossings until independence was achieved. Training continued daily. The cats' performances were filmed every 2 weeks until 16-20 weeks post-injury. For data collection, the cats' hindquarters were shaved and reflective spheres placed on the iliac crest, greater trochanter, lateral malleolus, and the base of the fifth metatarsal. A fifth marker was placed on the fibula $\sim 1$ inch above the lateral malleolus marker to generate a unit vector, which in combination with the measured length from the lateral malleolus to the head of the lateral condyle (length of the fibula), was used to automatically calculate the knee position using Motus software (Vicon Peak). Following a hemisection, the ipsilateral hindlimb shows the greatest deficits; therefore assessments predominantly focused on the left hindlimb (LH).

Recovery onset of independent crossing and integration of LH placement were determined for each cat at multiple post-injury time points. Independent crossing was defined by the ability to complete at least two full crossings without assistance. LH placement required that the LH be positioned and maintained with weight support on a peg. Once independent crossing recovered, the percentage of LH placements was quantified from the three best crossings at each time point. Interlimb coordination patterns between the four limbs were assessed during independent crossings using footfall and support pattern diagrams as well as support formulas during 10 step cycles/cat at 16 weeks post-injury. These assessments determine when each of the four limbs is in stance or swing phase and whether the timing of these phases is coordinated across the limbs and produces a predictable pattern. Interlimb coordination and limb placement data were analyzed frame-by-frame. Angular kinematics also were assessed from a minimum of 10 step cycles at this same time point.

Retrograde tracing. In 10 cats, the retrograde tracer Fluoro-Gold (FG) ( $0.5 \%$ in sterile water; Fluorochrome) was used to label RST neurons with axons extending below the level of the hemisection. One to 2 weeks following the 16 week data point collection, the lesion site was reexposed in a subset of cats and FG was injected bilaterally $\sim 15 \mathrm{~mm}$ below the caudal aspect of the lesion using a 33 gauge Hamilton syringe. To ensure 
adequate spread of the tracer across the entire cross-section of the spinal cord, the total $2 \mu \mathrm{l}$ volume of FG was delivered into 4 injection sites $(0.5$ $\mu \mathrm{l}$ each site). Within each site, half of the volume $(0.25 \mu \mathrm{l})$ was placed in the ventral half of the spinal cord and half into the dorsal half. No cats used in this study had FG spread into the lesion site.

Tissue processing and histology. Thirteen days following FG injections, cats were overdosed with sodium pentobarbital $(>40 \mathrm{mg} / \mathrm{kg}$, i.p. and supplemented i.v.) followed by $1 \mathrm{cc}$ of heparin (1000 U, i.v.) and, $20 \mathrm{~min}$ later, an injection of $1 \%$ sodium nitrite ( 1 cc, i.v.). Cats then were perfused transcardially with $0.9 \%$ saline followed by $4 \%$ paraformaldehyde in $0.1 \mathrm{~m}$ phosphate buffer, $\mathrm{pH}$ 7.4. The brain and spinal cords were removed, blocked, postfixed with $4 \%$ paraformaldehyde overnight, and placed in 30\% sucrose in $4 \%$ paraformaldehyde for cryoprotection. Frozen longitudinal sections $(25 \mu \mathrm{m})$ of the FG injection sites were cut serially into PBS using a cryostat, mounted onto Superfrost/Plus slides (Fisher Scientific), and coverslipped (Vectashield Hard Set Mounting Media for Fluorescence, Vector Laboratories). FG autofluorescence was assessed to verify that the tracer was distributed across the width and depth of the spinal cord but did not spread into the lesion site. Mid-brain and spinal cord lesion segments were cut serially in cross-section at 25 $\mu \mathrm{m}$ on a cryostat and collected in a $0.1 \mathrm{M}$ PBS solution ( $\mathrm{pH} 7.2$, saline $0.9 \%$ ). Every tenth section of the lesion and mid-brain was stained with cresyl violet (cresyl violet with acetate, Sigma-Aldrich) and myelin stains (Eriochrome Cyanine R; Fluka) as described previously (Howland et al., 1995b; Tester and Howland, 2008). The remaining sections were processed for immunohistochemistry.

Immunohistochemistry. To identify $\mathrm{p}-\mathrm{NF}-\mathrm{H}$ within and caudal to the lesion, sections were processed using the monoclonal chicken antiphosphorylated neurofilament heavy chain antibody (1:10,000, pNF-H; gift from G. Shaw and EnCor Biotechnology). Endogenous enzyme activity was quenched using $30 \% \mathrm{H}_{2} \mathrm{O}_{2}$ in PBS for $30 \mathrm{~min}$ and then the sections were rinsed with PBS. Sections were rinsed in $1 \%$ goat serum in PBS containing $0.4 \%$ Triton X-100 ( $1 \%$ S-PBS-T), blocked in $5 \%$ $\mathrm{S}$-PBS-T for $1 \mathrm{~h}$ at room temperature, and incubated with the primary antibody diluted in $1 \%$ S-PBS-T overnight at $4^{\circ} \mathrm{C}$. The next day tissue sections were rinsed with $1 \%$ S-PBS-T before and after a $1 \mathrm{~h}$ incubation with Alexa Fluor 488 (1:400, Invitrogen). Tissue sections were mounted onto charged slides and coverslipped using the ProLong Gold antifade reagent (Invitrogen).

To identify and count FG-labeled rubrospinal neurons, midbrain sections containing the RN were rinsed with $1 \%$ S-PBS-T, blocked with 5\% $\mathrm{S}$-PBS-T at room temperature for $1 \mathrm{~h}$ and incubated overnight at room temperature with rabbit anti-FG (1:10,000, Fluorochrome). Tissue sections were rinsed with $1 \%$ S-PBS-T the next day followed by incubation with an anti-rabbit mouse secondary antibody (Vector Laboratories). Signal amplification was accomplished with the avidin-biotin-complex (ABC) method (Vector Laboratories) and visualized with a 3,3'diaminobenzidine brownish reaction product (Sigma).

To visualize presynaptic terminals on FG-labeled RN neurons, double immunoperoxidase immunohistochemistry was done using monoclonal mouse anti-synaptophysin (1:1000, Sigma) and anti-FG antibodies. Tissue was processed as above for FG staining and then rinsed with $1 \%$ S-PBS-T and blocked with 5\% S-PBS-T at room temperature for $1 \mathrm{~h}$. This was followed by incubation in primary anti-synaptophysin overnight at $4^{\circ} \mathrm{C}$. The next day tissue sections were rinsed with $1 \%$ S-PBS-T followed by incubation with an anti-mouse secondary (Vector Laboratories). Signal amplification was accomplished with the $\mathrm{ABC}$ method and visualized with the Vector VIP peroxidase substrate kit (Vector Laboratories) to give a purplish reaction product. Sections were mounted onto chromium potassium sulfate and poly-L-lysine subbed slides, allowed to dry, dehydrated through increasing alcohol concentrations, placed into xylene and coverslipped using DPX (Fluka).

Stereological analysis of $\mathrm{pNF}-\mathrm{H}$. Tissue from eight cats was processed for pNF-H analyses. Three spinal cord cross-sections $300 \mu \mathrm{m}$ apart from each other, were used from control $(n=4)$ and Ch'ase ABC $(n=4)$ treated cats to assess the area fraction of pNF-H in four areas of the spinal cord caudal to the lesion epicenter: (1) ipsilateral gray matter; (2) ipsilateral white matter; (3) contralateral gray matter; and (4) contralateral white matter. The first of these sections in each animal was $1200 \mu \mathrm{m}$ caudal to the lesion epicenter. Pictures were taken $(10 \times$ objective $)$ of the entire extent of all four areas indicated and used for stereological investigation. Stereoinvestigator software (MBF Bioscience) was used to assess the fractional area of pNF-H immunoreactivity within these regions, across each section, and across cats using the area fraction fractionator probe and the following parameters: section sampling fraction: $1 / 12$; grid spacing: $250 \mu \mathrm{m} \times 500 \mu \mathrm{m}$ for the gray matter areas and $375 \mu \mathrm{m} \times 750$ $\mu \mathrm{m}$ for the white matter areas; Cavalieri spacing: $15 \mu \mathrm{m}$ in all areas examined; counting frame size: $100 \mu \mathrm{m} \times 100 \mu \mathrm{m}$ in all areas examined. The area fraction fractionator probe combines the Cavalieri grid point approach with the fractionator sampling method to examine the fraction of a given region occupied by a marker of interest (Howard and Reed, 2005). To define the areas ipsilateral to the lesion, tissue caudal to frank lesion damage was included. Inversely, areas contralateral to the lesion included tissue areas caudal to areas not damaged at the lesion epicenter.

Quantification of rubrospinal neurons. The left (spared) RN was used as an internal control in each animal. FG-labeled RST neurons in the left and right $\mathrm{RN}$ were quantified in each animal from every eighth section $(200 \mu \mathrm{m})$ throughout the rostrocaudal extent of each RN. Only neurons with visible punctate FG staining were counted. Neurons in the right (experimental) $\mathrm{RN}$ then were calculated as a percentage of the left (spared) $\mathrm{RN}$ as an internal control for individual animal differences.

Statistical analyses. Statistical analyses were performed using Statistical Package for the Social Sciences (SPSS, version 17). For the categorical behavioral data the Fisher's exact test was used due to the occurrence of cells with frequencies $<5$. Discrete, ordinal behavioral and anatomical data for independent samples (Ch'ase $\mathrm{ABC}$ versus Tris) were assessed using the Mann-Whitney $U$ test. All Fisher's exact and Mann-Whitney $U$ tests were two tailed and a value of $p<0.05$ was considered significant. Discrete, ordinal data for dependent samples (pre-SCI compared with post-SCI performance or comparison of different post-SCI time point performances within a group) were assessed using the Wilcoxon signed-rank test. All tests for this assessment were one tailed as performance was anticipated to change in only one direction and significance was set at $p<0.05$.

\section{Results}

\section{Spinal hemisections}

Cresyl violet- and myelin-stained serial sections were used to determine the extent of spinal cord damage. The lesions of all 22 cats were similar and typically showed complete ipsilateral gray and white matter damage. Variability across lesions was limited and three spinal cord sections representing the entire range of spinal hemisections are shown in Figure 1. The smallest lesion had some ipsilateral ventromedial white matter sparing (Fig. 1A) and the largest had some contralateral damage (Fig. $1 C$ ). The middle of this range is represented by a complete hemisection without any ipsilateral sparing or contralateral damage (Fig. $1 B$ ). Critical to the RN counts, the lateral funiculus where the RST is located was completely severed ipsilaterally and spared contralaterally in all cats.

\section{Ch'ase $\mathrm{ABC}$ enhances multiple features of peg walkway performance}

All cats showed an initial period $(<24 \mathrm{~h})$ of flaccid paralysis followed by reflex activity and then voluntary movement of the LH within 48-72 h of injury. Consistent with previous reports from our lab and others, basic LH stepping during bipedal treadmill and voluntary overground locomotion began to recover by the end of the first postoperative week (Eidelberg et al., 1986; Helgren and Goldberger, 1993; Tester and Howland, 2008).

Although all cats quickly, efficiently, and independently crossed the peg walkway before injury, the ability to accomplish this task was disrupted by hemisection (Fig. 2A). Recovery occurred gradually in all cats post-hemisection. Each time point presented reflects recovery that occurred over the intervening period between data collection points. At 2 weeks post-injury, few 

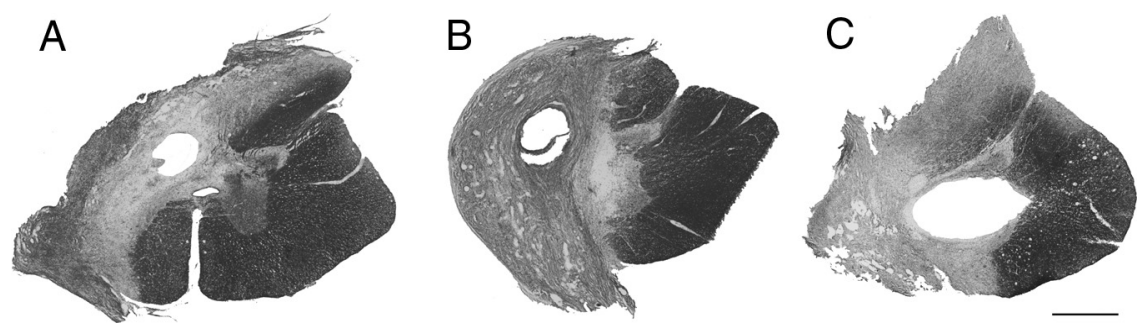

Figure 1. Spinal hemisections. $\boldsymbol{A}-\boldsymbol{C}$, Horizontal sections through the lesion epicenter stained with cresyl violet and myelin stains show that lesions ranged from an under-hemisection with ipsilateral ventromedial sparing $(\boldsymbol{A})$, to hemisection lesions with interruption of all ipsilateral gray and white matter $(\boldsymbol{B})$, to over-hemisections with interruption of contralateral gray and white matter (C). Scale bar, $1 \mathrm{~mm}$.

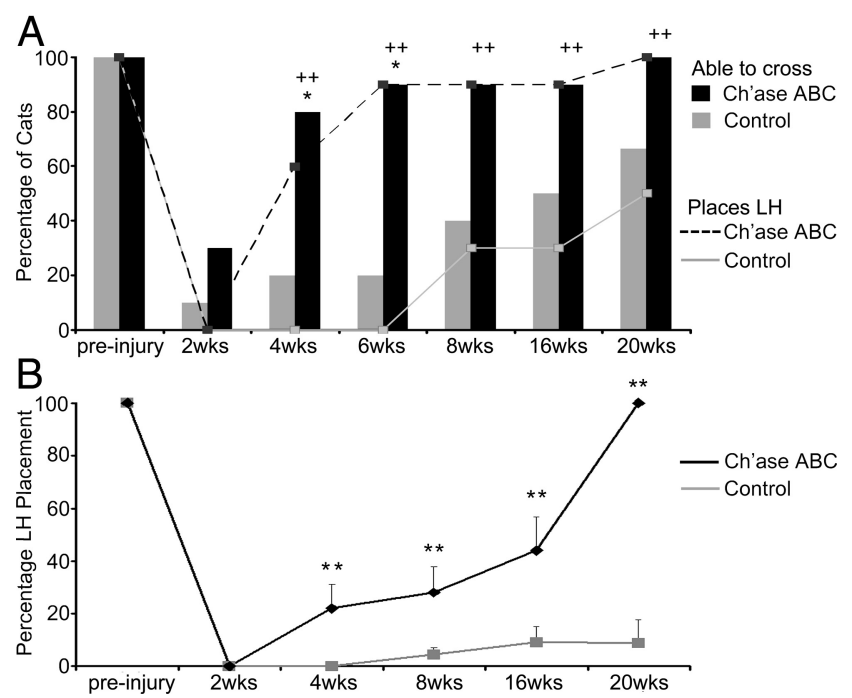

Figure 2. Peg walkway locomotor recovery is improved with Ch'ase $A B C$ administration. $\boldsymbol{A}$, The ability to cross the peg walkway (bar graphs) and place the LH on the pegs (line graphs) was assessed for Ch'ase ABC (black)-treated and control (gray)-treated cats pre- and post-injury. Pre-injury, all cats crossed the peg walkway and placed their LHs onto the pegs with $100 \%$ accuracy. Following injury, significantly more Ch'ase ABC-treated cats crossed independently at $4\left({ }^{*} p=0.023\right)$ and $6\left({ }^{*} p=0.005\right)$ weeks compared with controls. Significantly more Ch'ase ABC-treated cats also showed some placement of their LHs onto pegs at $4\left({ }^{++} p=0.011\right), 6$ $\left({ }^{++} p=0.001\right), 8\left({ }^{++} p=0.02\right), 16\left({ }^{++} p=0.02\right)$, and $20\left(^{++} p=0.033\right)$ weeks postinjury. $\boldsymbol{B}$, LH placement onto the pegs was quantified. Ch'ase $A B C$-treated cats accurately placed their LHs a greater percentage of step cycles compared with controls at $4\left({ }^{* *} p=0.005\right), 8\left({ }^{* *} p<0.012\right)$, $16\left({ }^{* *} p=0.009\right)$, and $20\left({ }^{* *} p=0.005\right)$ weeks post-injury. Error bars denote SEM.

cats ( 1 of 10 controls, 3 of 10 Ch'ase ABC) could cross the peg walkway independently and the small difference across groups was not significant ( $p=0.582$, Fisher's exact test). The number of Ch'ase ABC-treated cats crossing at 4 weeks post-SCI ( 8 of 10), however, was significantly greater than the number seen in the control group ( 2 of $10 ; p=0.023$ Fisher's exact test). This significant difference between the two groups' performances also was seen at 6 weeks ( $p=$ 0.005 , Fisher's exact test). By 8 weeks the number of Ch'ase ABCtreated ( 9 of 10) compared with control ( 4 of 10) cats was not significantly different ( $p=0.057$, Fisher's exact test). The differences between groups at 16 weeks ( 9 of 10 vs 5 of $10 ; p=0.141$ Fisher's exact test) and 20 weeks ( 10 of 10 vs 7 of $10 ; p=0.211$, Fisher's exact test) also were not significant. These results suggest that Ch'ase ABC treatment significantly accelerates recovery of balance skills necessary to cross, but recovery of this feature as assessed becomes similar between the two groups $\sim 8$ weeks post-injury.

Before injury, all cats crossed the peg walkway using four limbs. Following hemisection, however, cats might or might not ence between the two groups continued to be seen at 6 weeks $(p=0.001), 8$ weeks $(p=0.020), 16$ weeks $(p=0.020)$ and 20 weeks $(p=0.033)$ post-SCI.

To determine how effectively cats integrated their LHs during crossings and whether Ch'ase $\mathrm{ABC}$ enhanced recovery of this feature, the number of $\mathrm{LH}$ placements onto a peg were quantified (Fig. $2 B$ ). No significant differences in performance were seen pre-injury between the cats that would be placed into each group ( $p=1.0$, Mann-Whitney $U$ test) as all cats placed their LH onto a peg $100 \%$ of the time. There also was not a significant difference between the two groups at 2 weeks post-injury $(p=1.0)$ as none of the cats placed their LHs onto a peg. By 4 weeks, however, the average percentage of $\mathrm{LH}$ placements was significantly greater in the Ch'ase ABC-treated group (22\%) compared with the control group $(0 \% ; p=0.005$, Mann-Whitney $U$ test). The performance of the Ch'ase ABC-treated animals continued to show significantly greater LH placements at 8 weeks $(28 \%$ vs $5 \% ; p=0.012)$ and 16 weeks ( $44 \%$ vs $9 \%, p=0.009)$. Only 10 cats (4 Ch'ase $\mathrm{ABC}$-treated and 6 controls) remained in the study out to 20 weeks. Significant differences also were seen in this smaller number at 20 weeks post-injury ( $100 \%$ vs $9 \%, p=0.005)$.

To understand how this recovery occurs between time points within each group, additional assessments of the data using the Wilcoxon matched-pairs signed-rank test were performed. The control group of cats showed a significant decrease in LH peg placements at all time points compared with pre-injury performance: 2 weeks $(p=0.002), 4$ weeks $(p=0.002), 8$ weeks $(p=$ $0.008), 16$ weeks $(p=0.004)$, and 20 weeks $(p=0.020)$. As seen in the control group, the Ch'ase $\mathrm{ABC}$ group showed significant decreases in the number of LH placements at 2 weeks $(p=$ $0.002), 4$ weeks $(p=0.005), 8$ weeks $(p=0.008)$, and 16 weeks ( $p=0.018)$ post-injury compared with their pre-injury performances. In contrast to the control group, the LH performance of Ch'ase ABC-treated group at 20 weeks was not significantly different from pre-injury $(p=1.0)$ indicating that performance was similar to that seen pre-injury. Assessments also indicated that significant increases in performance were seen from 2 to 4 weeks $(p=0.028)$ and from 8 to 16 weeks $(p=0.012)$ in the Ch'ase $\mathrm{ABC}$ group. No significant improvements in performance were seen between any post-injury time points in the control group. Collectively these data on the use of the LH suggest that Ch'ase $\mathrm{ABC}$ significantly enhances the general integration of the hindlimb as well as the accuracy with which the limb is used.

Peg walkway crossing is characterized by interlimb coordination pre- and post-injury

Before injury, cats typically placed their left limbs (fore and hind) on the pegs on the left side of the board and their right limbs (fore and hind) on the right side pegs (Fig. $3 A$ ). This basic placement 


\section{A}

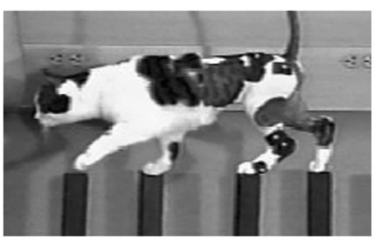

图 圆

国
B

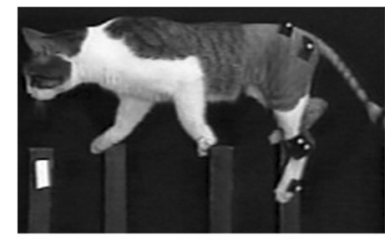

国

区
C

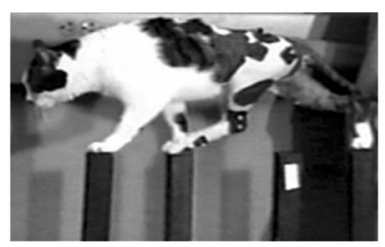

圆

E
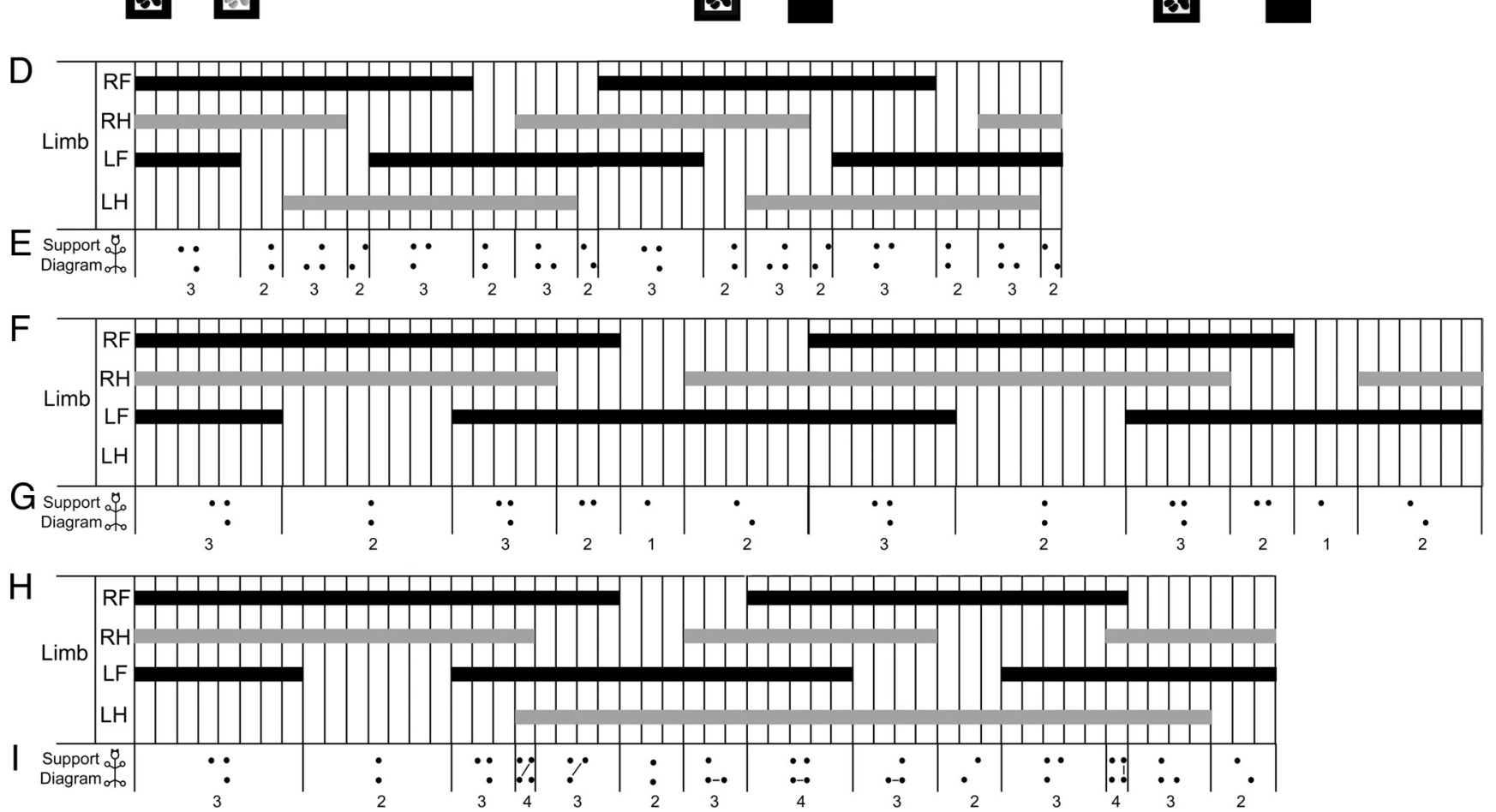

Figure 3. Interlimb coordination on the peg walkway. Pre-injury cats typically place their left limbs on the pegs on the left side of the board and the right limbs on the pegs on the right side. No two limbs occupy a peg at the same time $(\boldsymbol{A})$. Sixteen weeks post-injury, control-treated animals typically cross on three limbs and do not place their $L H s$ onto pegs $(\boldsymbol{B})$. C Ch'ase $A B C-$ treated cats can place their $L H s$ onto pegs $(\boldsymbol{C})$, but do so using a novel pattern in which the $L H$ is paired with the RF on a peg on the right side of the board $(\boldsymbol{C}, \boldsymbol{H})$. Footfall pattern diagrams also suggest differences in stance overlap and duration between pre-injury $(\boldsymbol{D})$ and 16 weeks post-injury in control-treated $(\boldsymbol{F})$ and $C \boldsymbol{h}^{\prime}$ ase ABC-treated $(\boldsymbol{H})$ cats. Solid bars indicate when the limb is in stance, and open areas indicate when the limb is in swing. Time between vertical lines is one video frame (33.3 $\mathrm{ms})$. Support pattern diagrams further illustrate the timing differences and the emergence of a single limb support period in the control-treated cats $(\boldsymbol{G})$ and a quad support period in the Ch'ase ABC-treated cats $(\boldsymbol{I})$, neither of which is seen pre-injury $(\boldsymbol{E})$. The support formulas shown with the support diagrams indicate that each group has a different, but consistent pattern. Hindpaws are gray and forepaws black ( $\boldsymbol{A}-\boldsymbol{C}$ ). Lines connecting limbs in the support pattern diagrams indicate pairing of the two limbs on the same peg. Two complete step cycles are shown in each example $(\boldsymbol{D}-\boldsymbol{I})$.

strategy is not seen post-injury. Cats that do not reintegrate their LHs simply do not place them (Fig. 3B). However, cats that reintegrated the $\mathrm{LH}$ crossed the body midline with this limb and placed it onto a peg on the right side of the board (Fig. 3C). Further, the LH was paired with the right forelimb (RF), for at least initial peg contact. Thus, the LH and RF shared a peg for some amount of time on the right side of the peg walkway (Fig. 3C).

Pre-injury, when the majority of cats (16 of 20) consistently kept their left and right limbs on the left and right sides of the peg walkway respectively, performances were characterized by a single, consistent footfall pattern that was repeated with the beginning of each step cycle (Fig. 3D). During the majority of the step cycle, only one limb at a time was in swing. The very brief periods in which the swing of two limbs coincided were typically 1-2 video frames in length, which is equivalent to 33-66 ms. The limbs paired during these brief swing phase overlaps showed a consistent, repeating pattern. Overlap of the ipsilateral forelimb and hindlimb swing phases occurred first followed by overlap of the contralateral forelimb and hindlimb swing phases. Additionally, initiation of the stance phases of the four limbs also occurred in a predictable order beginning with the $\mathrm{LH}$, followed by the left forelimb (LF), then right hindlimb (RH), and ending with the RF. Approximately $60 \%$ of each step cycle was characterized by triple limb support time and $\sim 40 \%$ by double limb support (Fig. 3D). Analyses using support pattern diagrams also indicated the use of a consistent interlimb coordination pattern. The support pattern diagrams showed a consistent 3-2-3-2-32-3-2 support formula (Fig. 3E). Thus, as has been shown in studies of cats during quadrupedal treadmill and voluntary overground locomotion (Miller and Van Der Meché, 1975; Miller et al., 1975a,b; Wetzel et al., 1975; Wetzel and Stuart, 1976; English, 1979, 1980, 1985; English and Lennard, 1982; Cruse and Warnecke, 1992; Blaszczyk and Loeb, 1993; Gorska et al., 1993; Howland et al., 1995a), steps on a peg walkway showed a consistent interlimb coordination pattern. 
Analyses of data from three control cats that were able to cross the peg walkway at 16 weeks post-injury, but unable to place the $\mathrm{LH}$, showed a consistent interlimb coordination. The total support time of the RF, RH, and LF was increased compared with pre-injury and a brief single support period was seen. The order of the stance and swing phases for the three limbs placing on the peg walkway relative to the others was similar to pre-injury patterns with the exception of $\mathrm{LH}$ placement (Fig. $3 F$ ). The support pattern diagrams also showed a consistent support formula of 3-2-3-2-1-2 for each step cycle (Fig. 3G). Therefore, footfall patterns and support diagrams both indicate that the ability to coordinate recovers, but the pattern is altered due to the use of only three limbs post-hemisection and lengthened support phases.

Analyses of data from three Ch'ase ABC-treated cats capable of integrating their LHs consistently at 16 weeks post-injury showed development of a novel, consistent interlimb coordination pattern across cats. The support times for RF and LF, as well as the LH were notably increased compared with pre-injury. In particular, the stance phase of the LH was lengthened such that it overlapped with at least two stance phases of each of the other limbs. These increases contributed to the introduction of a quadrupedal support period not seen in the other groups. The $\mathrm{LH}$ swing phase also was notably lengthened. The increased time spent in each of these phases by the LH resulted in a 1:2 ratio of the LH step cycle to the step cycles of each of the other limbs. The general order of the stance and swing phases for each limb relative to the others showed a similarity to the pre-injury pattern with the exception of the LH (Fig. 3H). The support pattern diagrams (Fig. 3I) also showed a consistent interlimb coordination pattern. Unlike pre-injury and controls, two alternating formulas were seen. These formulas were 3-2-3-4-3-2-3 for the first step cycle and 4-3-2-3-4-3-2 for the subsequent step cycle. Thus, footfall patterns and support diagrams indicate that the post-hemisection + Ch'ase $\mathrm{ABC}$ pattern showed some similarities to pre-injury performance, but also some unique features.

The LH proximal angular kinematic patterns showed distinctly different ranges of movement in cats that placed their LHs on pegs versus those that did not. Although control animals typically crossed the peg walkway on three limbs, the LH was not passive. It showed alternating flexion and extension. Angular excursions always differed from pre-injury values, but no consistent angular kinematic patterns were seen across cats post-injury (Fig. $4 A$ ). In contrast, the angular kinematics of the proximal LH of Ch'ase ABC-treated cats that placed post-injury consistently showed nearly twice the range of angular excursion at the hip and the knee compared with pre-injury values (Fig. 4B). The increased angular excursions are consistent with the placement of the LH on the right side pegs and the skipping of a peg due to the 1:2 ratio of LH stepping to each of the other limbs. Peg skipping on the right side of the peg walkway by the LH post-injury was in contrast to LH placement onto every peg on the left side of the peg walkway pre-injury. Collectively, these results suggest that Ch'ase $\mathrm{ABC}$ cats develop unique but consistent and effective new $\mathrm{LH}$ movement strategies post-hemisection for crossing the peg walkway, and that despite nonplacement of the LH onto the peg walkway for control animals, there also is a predictable coordination pattern between the three supporting limbs.

\section{Ch'ase $\mathrm{ABC}$ is associated with increased axonal density}

Axonal growth was assessed qualitatively within the lesion epicenter using an antibody against the $200 \mathrm{kDa}$ phosphorylated axonal form of pNF-H. pNF-H-positive axonal profiles were visible throughout the lesion scar in all animals (Ch'ase $\mathrm{ABC}$ and
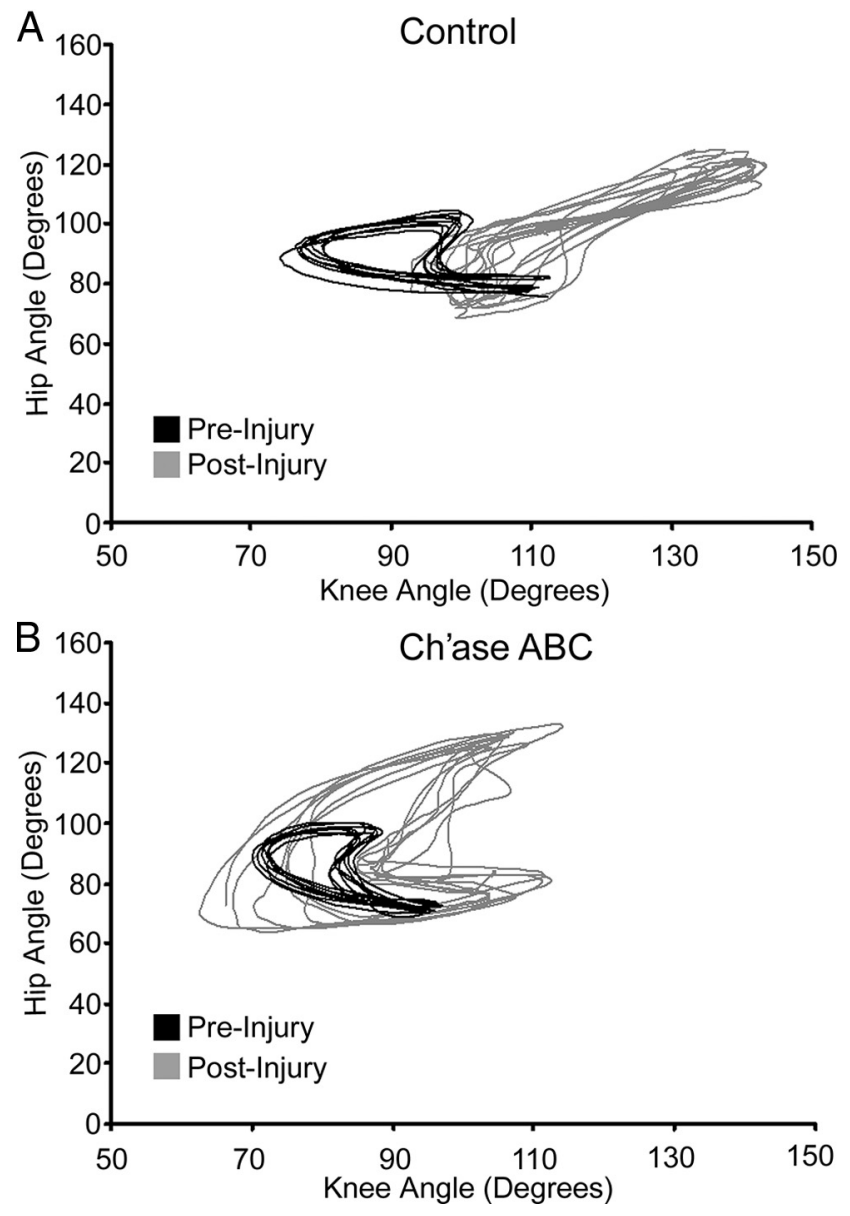

Figure 4. Hip and knee angular kinematics on the peg walkway. Pre-injury movement patterns (black; $\boldsymbol{A}, \boldsymbol{B}$ ) may vary some across cats but are consistent within each cat and used as a baseline for intra-animal pre-post comparisons. $A$, An example from 16 weeks post-injury in a control-treated cat shows that the ranges of hip and knee movements are much greater and more extended in the non-placing LH (gray) than were seen pre-injury. $\boldsymbol{B}$, The angular excursions of the hip and knee also are much greater in the LHs of Ch'ase ABC-treated cats 16 weeks post-injury (gray) compared with pre-injury (black). However, as seen in this example, the coordination between the two joints appears similar to pre-injury (note crescent shapes) and the greater excursion is consistent with the skipping of every other peg by the LH. Smaller joint values on either axis represent increased flexion of the joint being assessed, and larger values represent increased joint extension. At each time point, representative step cycles are shown.

controls) assessed. This indicates that the lesion environment in all cats was permissive for some axonal growth. pNF-H staining density, however, was not assessed as the size of the scar area varied notably across cats and would have confounded any findings between groups.

The density of pNF-H profiles were quantitatively assessed (4 Ch'ase $\mathrm{ABC}$-treated and 4 controls) throughout the ipsilateral and contralateral gray and white matter caudal to the spinal hemisections. The area fractions of pNF-H immunoreactivity within the caudal ipsilateral gray matter (Fig. $5 D, E$ ) and contralateral white matter (Fig. $5 F, G$ ) were not significantly different between Ch'ase ABC- and control-treated cats (Mann-Whitney $U$ test, $p=0.166$ for each). In contrast, Ch'ase ABC-treated cats had a significantly greater area fraction of pNF-H immunoreactivity in the caudal ipsilateral white matter compared with controls ( $p=0.033$, Fig. $5 A ; B, C)$. Ch'ase ABC-treated cats also had a significantly greater area fraction of pNF-H in the caudal contralateral gray matter compared with controls ( $p=0.003$; Fig. $5 A, H, I)$. 
A

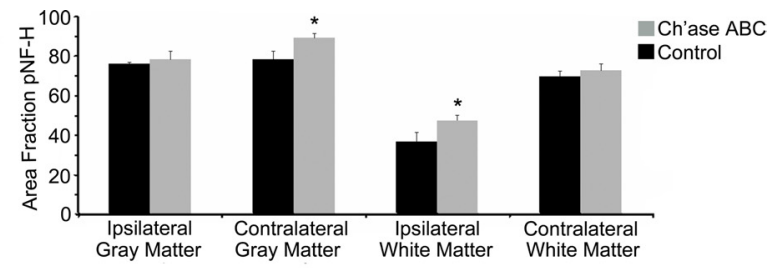

Control
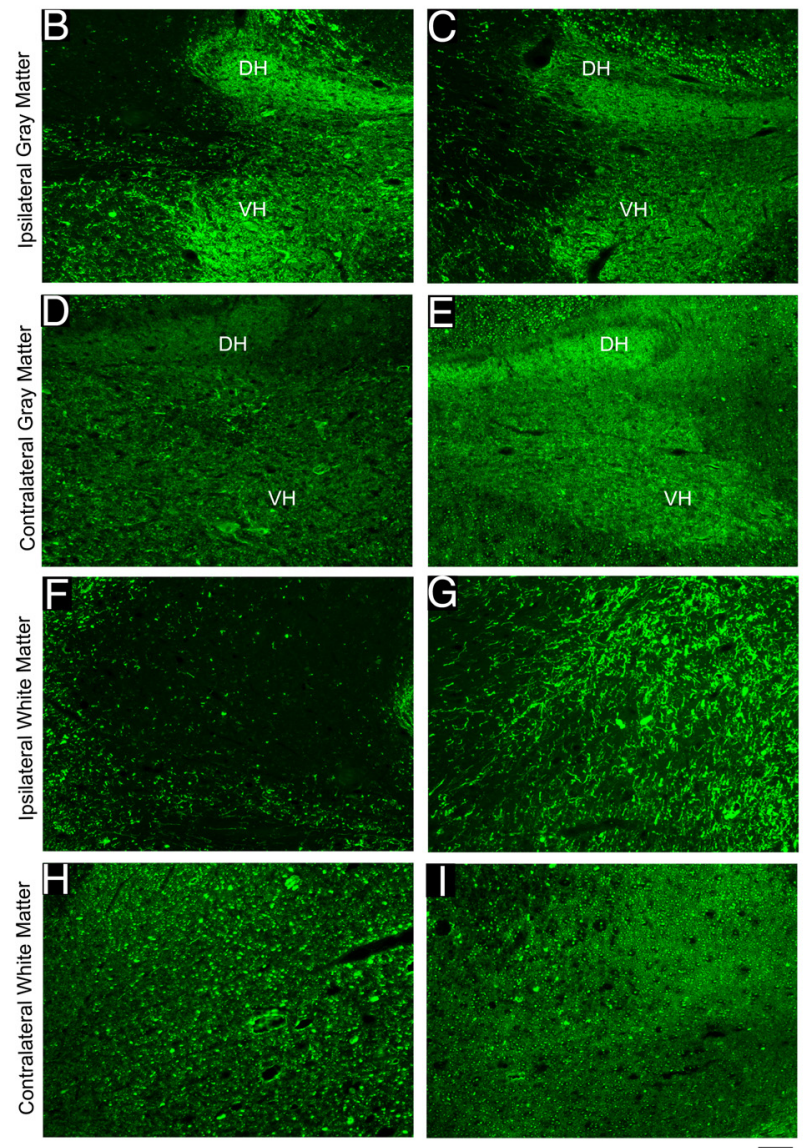

Figure 5. Increased pNF-H caudal to the lesion following Ch'ase $A B C$ treatment. Nonbiased stereological quantification of the area fraction of pNF-H $(\boldsymbol{A})$ was assessed in four regions of the spinal cord: ipsilateral gray matter $(\boldsymbol{B}, \boldsymbol{C})$, contralateral gray matter $(\boldsymbol{D}, \boldsymbol{E})$, ipsilateral white matter $(\boldsymbol{F}, \boldsymbol{G})$, and contralateral white matter $(\boldsymbol{H}, \boldsymbol{I})$. The pNF-H-positive area was significantly greater in $C h$ 'ase $A B C$-treated animals compared with controls in the contralateral gray matter $\left(\boldsymbol{A} ; \boldsymbol{D}, \boldsymbol{E} ;{ }^{*} p=0.003\right)$ and ipsilateral white matter $\left(\boldsymbol{A} ; \boldsymbol{F}, \boldsymbol{G} ;{ }^{*} p=0.033\right)$. There was no significant difference between groups in the ipsilateral gray matter $(\boldsymbol{A} ; \boldsymbol{B}, \boldsymbol{C})$ or contralateral white matter $(\boldsymbol{A} ; \boldsymbol{H}, \boldsymbol{I})$. Error bars denote SEM. Photomicrograph examples shown are from one $\mathrm{Ch}^{\prime}$ ase $A B C$ and one control cat. The dorsal horn $(\mathrm{DH})$ and ventral horn $(\mathrm{VH})$ are shown in the ipsilateral and contralateral gray matter examples $(\boldsymbol{B}-\boldsymbol{E})$. The ipsilateral and contralateral white matter $(\boldsymbol{F}-\boldsymbol{I})$ examples are from the lateral funiculus. Scale bar, $0.1 \mathrm{~mm}$.

More rubrospinal neurons have axons caudal to the hemisection in Ch'ase ABC-treated cats

To determine whether rubrospinal axons represent a portion of the increased pNF-H immunoreactivity seen caudal to the lesion, retrograde tract-tracing studies were conducted using FG in 10 cats ( 5 controls and 5 Ch'ase ABC-treated cats). Bilateral injections of FG were made $\sim 1.5-2$ segments below the original left, T9/10 lateral hemisection. The injections sites of all 10 cats showed a good distribution of the tracers across the entire crosssectional area, but did not spread into the lesion site. FG-labeled neurons in the left (control) RN were found throughout the hindlimb region of the magnocellular portion of the RN (Fig.
$6 A)$. The number of FG-labeled rubrospinal neurons in the left (control) RN was not significantly different between Ch'ase ABC and control animals (740 \pm 40 and $894 \pm 109$, respectively). The number of retrogradely labeled neurons in the right (axotomized) $\mathrm{RN}$, however, was greatly decreased compared with the left (Fig. 6A vs 6B). Ch'ase ABC-treated cats had an average of $308 \pm 59$ compared with $137 \pm 43$ FG-positive neurons in the controls. These averages then were expressed as a percentage of the number of labeled neurons in the left (control) RN. The percentage of neurons in the Ch'ase ABC-treated cats $(23 \%)$ was significantly greater than in the control cats (8\%) (Mann-Whitney $U$ test, $p=0.032$; Fig. $6 C$ ).

Some brainstem sections stained for FG throughout the RN also were double labeled with synaptophysin, a presynaptic terminal marker. Synaptophysin-labeled puncta were visualized on the perimeter of FG-labeled neurons in the left (control) RN (Fig. $6 D)$. Synaptophysin colocalized around FG-labeled neurons in the right (axotomized) $\mathrm{RN}$ in control-treated cats (Fig. 6E) as well as in Ch'ase ABC-treated cats (Fig. 6 F), suggesting that these neurons were receiving input.

\section{Discussion}

\section{Summary of results}

In the present study, we show that intraspinal Ch'ase $\mathrm{ABC}$ treatment enhanced adaptations in limb trajectories and forelimbhindlimb coordination following spinal hemisections in adult cats. When crossing a peg walkway, Ch'ase $\mathrm{ABC}$-treated cats were able to integrate the ipsilateral LH earlier and significantly more at all post-injury time points compared with controls. Further, the LH was integrated in a coordinated, predictable fashion resulting in a consistent forelimb-hindlimb pattern. In subgroups of cats used for quantitative histological analyses, significantly more axons were seen in the ipsilateral white matter and contralateral gray matter below the lesion in Ch'ase ABC versus control cats. Tract tracing analysis showed that the RST contributed to this increased axonal population. Specifically, significantly more $\mathrm{RN}$ neurons in the axotomized nucleus of Ch'ase $\mathrm{ABC}$ cats had axons below the hemisection than in controls. The RST is of particular interest as it is a major descending motor pathway associated with skilled movements in the normal cat (Widajewicz et al., 1994; Lavoie and Drew, 2002) and previously has been reported to respond favorably to Ch'ase $\mathrm{ABC}$ treatment after cervical hemisection in the rat (Yick et al., 2004). Thus, the current study suggests that treatment with Ch'ase $\mathrm{ABC}$ can enhance adaptive movement features critical for skilled types of locomotion and promote plasticity in the thoracic spinal cord of pathways typically associated with these features in normal cats.

\section{Limb trajectory control}

Intraspinal networks contain pattern-generating circuitry necessary for basic coordinated stepping on a treadmill without input from supraspinal systems (Grillner and Zangger, 1979; Giuliani and Smith, 1987; Rossignol and Dubuc, 1994; Howland et al., 1995b; Rossignol et al., 1996). Supraspinal input is required during basic voluntary overground locomotion to initiate stepping. Limb trajectory adaptations necessary for successful negotiation in a changing environment, however, require ongoing corticospinal (CST) and RST (Beloozerova and Sirota, 1993; Widajewicz et al., 1994; Drew et al., 1996; Lavoie and Drew, 2002; Beloozerova et al., 2010). For example, the CST is active during visually guided anticipatory gait modifications in response to an obstacle (Drew et al., 1996). Similarly, the RST is recruited during alterations of limb trajectory in response to environmental demands and addi- 

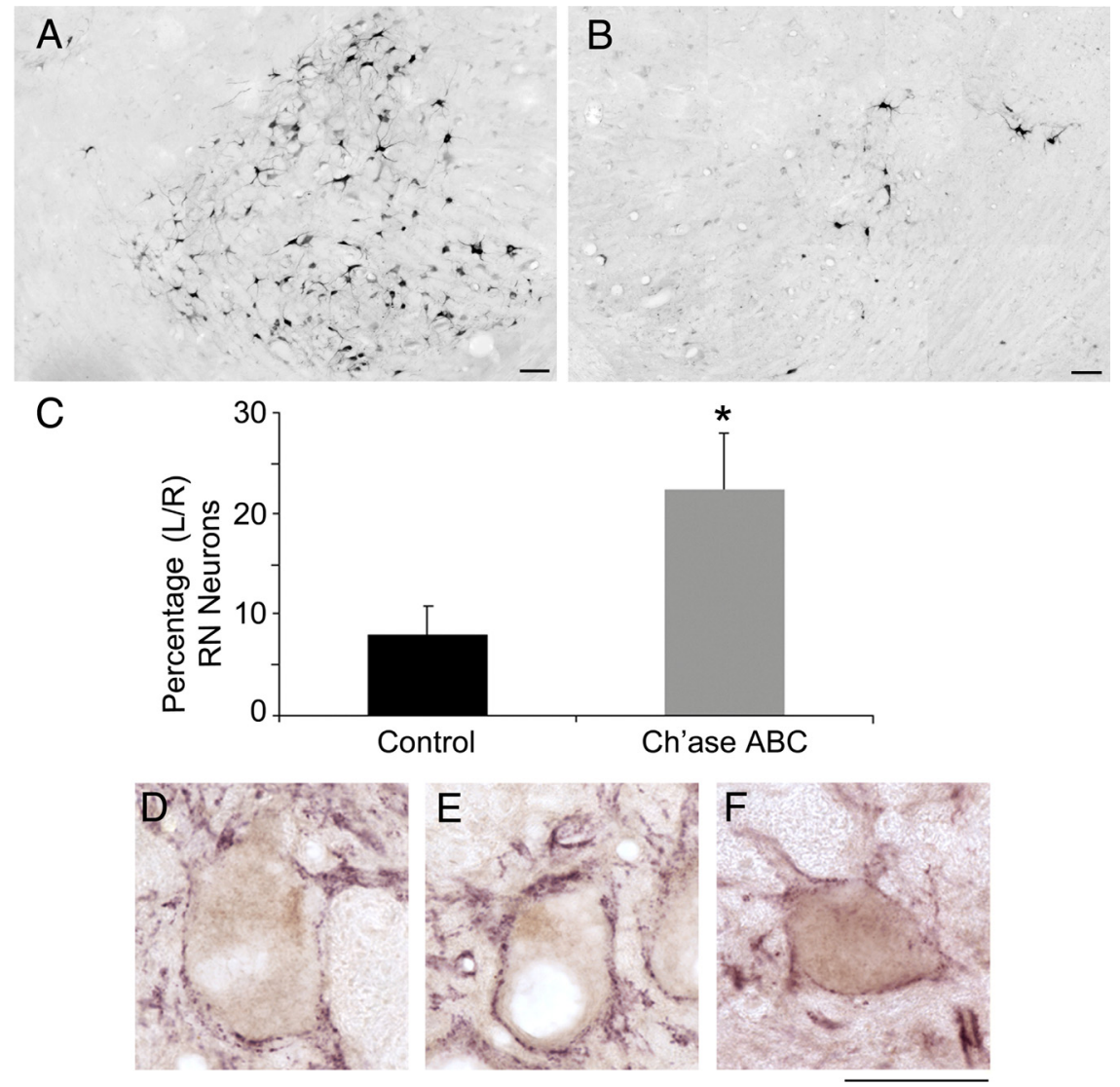

Figure 6. Retrograde labeling of red nuclei neurons from below the lesion. $A-C$, FG retrogradely labeled neurons in control (left) $(\boldsymbol{A})$ and experimental (axotomized) $(\boldsymbol{B})$ red nuclei were counted. Significantly more neurons were labeled in the experimental nuclei of $C h^{\prime}$ ase $A B C$-treated compared with control-treated cats $(\boldsymbol{C}$. The number of neurons labeled in the experimental red nuclei are presented as a percentage of the number labeled in control nuclei, ${ }^{*} p=0.032$. Error bars denote SEM. Scale bar, $0.1 \mathrm{~mm} . \boldsymbol{D}-\boldsymbol{F}$, Retrogradely labeled neurons in the control nuclei $(\boldsymbol{D})$ and experimental nuclei from control-treated $(\boldsymbol{E})$ and Ch'ase ABC-treated $(\boldsymbol{F})$ cats all showed costaining for the presynaptic terminal marker synaptophysin (purple), suggesting that these neurons (brown) were receiving input. Scale bar, $0.05 \mathrm{~mm}$.

tionally contributes to regulation of intra- and interlimb coordination (Lavoie and Drew, 2002). Peg walkway crossing assessed in the current study requires very precise limb placement and interlimb coordination and is accomplished easily by the normal cat. Following spinal hemisection, balance is affected and not all cats recover the ability to cross. Further, those that cross typically cannot alter their limb trajectories to accurately place their ipsilateral hindlimbs and therefore cross on three limbs. Ch'ase ABC-treated cats, however, recover the ability to place their ipsilateral hindlimbs on the peg walkway. Although trajectory adaptation and paw placement precision recovers in the Ch' ase $\mathrm{ABC}$-treated group, some features related to integration of the ipsilateral hindlimb, such as midline crossing, peg choice, and prolonged support periods, are distinctly different compared with pre-injury. This suggests that post-injury movement patterns, particularly after Ch'ase ABC treatment, likely are a combination of recovery and compensation (Levin et al., 2009). Regardless, it is likely that one or more descending supraspinal systems contribute to these ipsilateral hindlimb movements.

\section{Interlimb coordination}

Forelimb-hindlimb coordination patterns have been well defined in the cat during basic overground locomotion and quadrupedal stepping on a treadmill (Miller et al., 1973b; Stuart et al., 1973; Wetzel et al., 1975, 1977; Miller and van der Meché, 1976; Eisenstein et al., 1977; Coss et al., 1978; English, 1979, 1980; Forssberg et al., 1980a,b; English and Lennard, 1982; Cruse and Warnecke, 1992; Blaszczyk and Loeb, 1993; Howland et al., 1995a). Long propriospinal pathways connecting the cervical and lumbosacral levels of the spinal cord are believed to mediate this coordination (Miller et al., 1973a,b, 1975a; Miller and van der Meché, 1976) with modulation from supraspinal areas (Drew et al., 2004; Courtine et al., 2005). Further, a recent report shows the posterior parietal cortex contributes to interlimb coordination during obstacle negotiation (Lajoie et al., 2010). Consistent with what is known for basic forms of locomotion, we show that a consistent interlimb coordination pattern is present during peg walkway crossing in normal cats. This result, in combination with the recent report on obstacle negotiation, suggests that forelimb-hindlimb coordination also is characteristic of skilled forms of locomotion in which limb trajectories must be adapted. Despite the fact that cats cross the peg walkway on three limbs post-hemisection, a predictable forelimb-hindlimb pattern is present suggesting, as has been shown for basic overground locomotion (Kato et al., 1984), that sparing in this model is sufficient to support interlimb coordination. Although order and support patterns of the three limbs are similar to pre-injury, the support phases are consistently longer. In Ch'ase ABC-treated cats, integration of the ipsilateral hindlimbs occurs in a consistent manner, but timing with respect to the other three limbs is not similar to that seen pre-injury. Despite this compensatory integration, the recovered interlimb coordination pattern among the other limbs is not disrupted. This suggests that integration of the ipsilateral hindlimb likely is dependent upon alternative connections affected by Ch'ase $\mathrm{ABC}$ treatment that interact with preserved circuitry responsible for the coordination between the other three limbs.

\section{Axonal contributions increased in Ch'ase $\mathrm{ABC}$-treated cats}

Cytoskeletal disruption including degradation of neurofilament proteins occurs following SCI (Martin et al., 1990; Banik et al., 1997, 1982; Schumacher et al., 1999; von Euler et al., 2002; Liu et al., 2009) and axonal loss is significant and permanent even in partial lesion models like the hemisection (Bregman, 1987; Helgren and Goldberger, 1993). Analysis of the area fraction of pNF-H in the current study suggests that intraspinal Ch'ase ABC delivery in cats can increase axonal contributions immediately below the level of the lesion. Further, through retrograde tracing we show that neurons in the axotomized RN make a contribution to this axonal growth in Ch'ase $\mathrm{ABC}$-treated cats. Due to its contributions to adaptive motor control in the normal cat (Widajewicz et al., 1994; Lavoie and Drew, 2002), the RST is a likely candidate to contribute to the functional recovery seen. The motor skills seen also could be supported by a number of other pathways including the CST (Widajewicz et al., 1994; Drew et al., 
1996, 2002) and the long propriospinal pathways (Bareyre et al., 2004). These and additional connections are being tested in other studies within the lab. Regardless of the specific long tracts contributing to the motor responses, their input must cross the lesion site to affect the hindlimb. The current data suggest that RST axons from the axotomized $\mathrm{RN}$ can bridge the lesion site. Input from rostral systems also may be relayed across the lesion through spared and/or novel circuitry. In particular, studies in the rodent indicate that reorganization of descending supraspinal and propriospinal circuitry in the cervical spinal cord can mediate forelimb (Blagoveshchenskii et al., 2005) and hindlimb movements (Bareyre et al., 2004) typically dependent upon more direct CST input. Further, bridging of a thoracic injury by short propriospinal connections in the absence of other tracts may support voluntary stepping (Courtine et al., 2008, 2009). How Ch'ase ABC may directly or indirectly influence the extent of these novel or alternative circuitries is unknown.

\section{Conclusion}

Behavior changes in the current study continue for months after Ch'ase ABC treatment has ended (i.e., improvement in accurate limb placement). Our prior work (Tester and Howland, 2008) and assessments of the lesion areas in the current study (data not shown) at 16 and 20 weeks post-injury show CS GAGs are high in the lesion area at these times points. Although Brückner et al. (1998) showed that a single injection of Ch'ase ABC causes a sustained partial decrease in CSPG components for 8-12 weeks, in the best scenario this would still not cover the extended recovery timeframe seen in the current study. Based upon the best evidence showing that there is substantial reorganization following SCI which supports functional recovery (Bareyre et al., 2004; Courtine et al., 2008, 2009), this study raises the possibility that cleavage with Ch'ase $\mathrm{ABC}$ may promote plasticity that on an extended basis makes the nervous system more responsive to training and/or capable of supporting functional change.

All animals in the present study received training pre- and post-injury. Based upon a number of studies, this training may have contributed to the performance of the controls (Lovely et al., 1986; de Leon et al., 1998; Edgerton et al., 2004; Girgis et al., 2007; Boulenguez and Vinay, 2009; Sandrow-Feinberg et al., 2009; Krajacic et al., 2010; Wessels et al., 2010) as well as the performance of those that received Ch'ase ABC (García-Alías et al., 2009). Locomotor training also has been shown to increase the function of specific motor tracts including the CST (Thomas and Gorassini, 2005). Although these potential training issues need to be addressed carefully in future studies, the current results strongly suggest that Ch'ase $\mathrm{ABC}$ significantly can enhance adaptive features of locomotor function and axonal growth below the lesion when Ch'ase ABC is delivered for 4 weeks immediately post-SCI. Further, the use of the larger, more complex cat model enhances the potential for translation of these effects due to the distance requirements for growth across the lesion and the significant balance and sophisticated limb control required to accomplish the task assessed. To continue to move toward translation of Ch'ase ABC into a clinical setting, studies must be designed with attention to clinical relevance. An important issue not addressed in the current study is treatment delay. With few exceptions (Tom et al., 2009; Karimi-Abdolrezaee et al., 2010; Carter et al., 2011), most studies have investigated the impact of Ch'ase ABC by immediately initiating delivery post-injury. Understanding the effects of delaying treatment for varying periods is important not only for individuals with chronic injuries, but also to mimic even the short period (e.g., a day) that might be necessary to initiate a surgical intervention in an acute injury situation.

The current results are consistent with prior studies indicating that Ch'ase $\mathrm{ABC}$ can enhance plasticity by disrupting the growth inhibitory CS GAGs (for review, see Silver and Miller, 2004; Bradbury and Carter, 2011; Jakeman et al., 2011) and decrease axonal retraction post-SCI (Busch et al., 2009). They also provide new information regarding the effects of Ch'ase $\mathrm{ABC}$ on adaptive features of locomotion including limb trajectories, placement accuracy, interlimb coordination, and how these changes combine with non-Ch'ase ABC-mediated plasticity seen in controls. Although significant plasticity appears to occur post-SCI (for review, see Raineteau and Schwab, 2001), how it is enhanced, blended, or disrupted by addition of therapeutic agents typically is not addressed.

\section{References}

Armstrong DM (1986) Supraspinal contributions to the initiation and control of locomotion in the cat. Prog Neurobiol 26:273-361.

Armstrong DM (1988) The supraspinal control of mammalian locomotion. J Physiol 405:1-37.

Armstrong DM, Marple-Horvat DE (1996) Role of the cerebellum and motor cortex in the regulation of visually controlled locomotion. Can J Physiol Pharmacol 74:443-455.

Banik NL, Matzelle DC, Gantt-Wilford G, Osborne A, Hogan EL (1997) Increased calpain content and progressive degradation of neurofilament protein in spinal cord injury. Brain Res 752:301-306.

Banik NL, Hogan EL, Powers JM, Whetstine LJ (1982) Degradation of cytoskeletal proteins in experimental spinal cord injury. Neurochem Res 7:1465-1475.

Barbeau H, McCrea DA, O’Donovan MJ, Rossignol S, Grill WM, Lemay MA (1999) Tapping into spinal circuits to restore motor function. Brain Res Brain Res Rev 30:27-51.

Bareyre FM, Kerschensteiner M, Raineteau O, Mettenleiter TC, Weinmann O, Schwab ME (2004) The injured spinal cord spontaneously forms a new intraspinal circuit in adult rats. Nat Neurosci 7:269-277.

Barrière G, Leblond H, Provencher J, Rossignol S (2008) Prominent role of the spinal central pattern generator in recovery of locomotion after partial spinal cord injuries. J Neurosci 28:3976-3987.

Behrman AL, Harkema SJ (2000) Locomotor training after human spinal cord injury: a series of case studies. Phys Ther 80:688-700.

Beloozerova IN, Sirota MG (1993) The role of the motor cortex in the control of vigour of locomotor movements in the cat. J Physiol 461:27-46.

Beloozerova IN, Farrell BJ, Sirota MG, Prilutsky BI (2010) Differences in movement mechanics, electromyographic, and motor cortex activity between accurate and nonaccurate stepping. J Neurophysiol 103:2285-2300.

Blagoveshchenskii ED, Pettersson LG, Perfil'ev SN (2005) Control of fine movements mediated by propriospinal neurons. Neurosci Behav Physiol 35:299-304.

Blaszczyk J, Loeb GE (1993) Why cats pace on the treadmill. Physiol Behav 53:501-507.

Boulenguez P, Vinay L (2009) Strategies to restore motor functions after spinal cord injury. Curr Opin Neurobiol 19:587-600.

Bradbury EJ, Carter LM (2011) Manipulating the glial scar: chondroitinase $\mathrm{ABC}$ as a therapy for spinal cord injury. Brain Res Bull 84:306-316.

Bradbury EJ, Moon LD, Popat RJ, King VR, Bennett GS, Patel PN, Fawcett JW, McMahon SB (2002) Chondroitinase ABC promotes functional recovery after spinal cord injury. Nature 416:636-640.

Braughler JM, Hall ED, Means ED, Waters TR, Anderson DK (1987) Evaluation of an intensive methylprednisolone sodium succinate dosing regimen in experimental spinal cord injury. J Neurosurg 67:102-105.

Bregman BS (1987) Development of serotonin immunoreactivity in the rat spinal cord and its plasticity after neonatal spinal cord lesions. Brain Res 431:245-263.

Brückner G, Bringmann A, Härtig W, Köppe G, Delpech B, Brauer K (1998) Acute and long-lasting changes in extracellular-matrix condroitinsulphate proteoglycans induced by injection of chondroitinase $\mathrm{ABC}$ in the adult rat brain. Exp Brain Res 121:300-310.

Busch SA, Silver J (2007) The role of extracellular matrix in CNS regeneration. Cur Opin Neurobiol 17:120-127. 
Busch SA, Horn KP, Silver DJ, Silver J (2009) Overcoming macrophagemediated axonal dieback following CNS injury. J Neurosci 29:9967-9976.

Carter LM, McMahon SB, Bradbury EJ (2011) Delayed treatment with chondroitinase $\mathrm{ABC}$ reverses chronic atrophy of rubrospinal neurons following spinal cord injury. Exp Neurol 228:149-156.

Coss L, Chan AK, Goslow GE Jr, Rasmussen S (1978) Ipsilateral limb variation in cats during overground locomotion. Brain Behav Evol 15:85-93.

Courtine G, Roy RR, Raven J, Hodgson J, McKay H, Yang H, Zhong H, Tuszynski MH, Edgerton VR (2005) Performance of locomotion and foot grasping following a unilateral thoracic corticospinal tract lesion in monkeys (Macaca mulatta). Brain 128:2338-2358.

Courtine G, Song B, Roy RR, Zhong H, Herrmann JE, Ao Y, Qi J, Edgerton VR, Sofroniew MV (2008) Recovery of supraspinal control of stepping via indirect propriospinal relay connections after spinal cord injury. Nat Med 14:69-74.

Courtine G, Gerasimenko Y, van den Brand R, Yew A, Musienko P, Zhong H, Song B, Ao Y, Ichiyama RM, Lavrov I, Roy RR, Sofroniew MV, Edgerton VR (2009) Transformation of nonfunctional spinal circuits into functional states after the loss of brain input. Nat Neurosci 12:1333-1342.

Crespo D, Asher RA, Lin R, Rhodes KE, Fawcett JW (2007) How does chondroitinase promote functional recovery in the damaged CNS? Exp Neurol 206:159-171.

Cruse H, Warnecke H (1992) Coordination of the legs of a slow-walking cat. Exp Brain Res 89:147-156.

de Leon RD, Hodgson JA, Roy RR, Edgerton VR (1998) Locomotor capacity attributable to step training versus spontaneous recovery after spinalization in adult cats. J Neurophysiol 79:1329-1340.

de Leon RD, Roy RR, Edgerton VR (2001) Is the recovery of stepping following spinal cord injury mediated by modifying existing neural pathways or by generating new pathways? A perspective. Phys Ther 81:1904-1911.

Drew T, Jiang W, Kably B, Lavoie S (1996) Role of the motor cortex in the control of visually triggered gait modifications. Can J Physiol Pharmacol 74:426-442.

Drew T, Jiang W, Widajewicz W (2002) Contributions of the motor cortex to the control of the hindlimbs during locomotion in the cat. Brain Res Brain Res Rev 40:178-191.

Drew T, Prentice S, Schepens B (2004) Cortical and brainstem control of locomotion. Prog Brain Res 143:251-261.

Edgerton VR, Tillakaratne NJ, Bigbee AJ, de Leon RD, Roy RR (2004) Plasticity of the spinal neural circuitry after injury. Annu Rev Neurosci 27:145-167.

Eidelberg E, Nguyen LH, Deza LD (1986) Recovery of locomotor function after hemisection of the spinal cord in cats. Brain Res Bull 16:507-515.

Eisenstein BL, Postillion FG, Norgren KS, Wetzel MC (1977) Kinematics of treadmill galloping by cats. Behav Biol 21:89-106.

English AW (1979) Interlimb coordination during stepping in the cat: an electromyographic analysis. J Neurophysiol 42:229-243.

English AW (1980) Interlimb coordination during stepping in the cat: effects of dorsal column section. J Neurophysiol 44:270-279.

English AW (1985) Interlimb coordination during stepping in the cat: the role of the dorsal spinocerebellar tract. Exp Neurol 87:96-108.

English AW, Lennard PR (1982) Interlimb coordination during stepping in the cat: in-phase stepping and gait transitions. Brain Res 245:353-364.

Forssberg H, Grillner S, Halbertsma J (1980a) The locomotion of the low spinal cat. I. Coordination within a hindlimb. Acta Physiol Scand 108:269-281.

Forssberg H, Grillner S, Halbertsma J, Rossignol S (1980b) The locomotion of the low spinal cat. II. Interlimb coordination. Acta Physiol Scand 108:283-295.

García-Alías G, Barkhuysen S, Buckle M, Fawcett JW (2009) Chondroitinase $\mathrm{ABC}$ treatment opens a window of opportunity for task-specific rehabilitation. Nat Neurosci 12:1145-1151.

Gibson AR, Houk JC, Kohlerman NJ (1985) Magnocellular red nucleus activity during different types of limb movement in the macaque monkey. J Physiol 358:527-549.

Girgis J, Merrett D, Kirkland S, Metz GA, Verge V, Fouad K (2007) Reaching training in rats with spinal cord injury promotes plasticity and task specific recovery. Brain 130:2993-3003.

Giuliani CA, Smith JL (1987) Stepping behaviors in chronic spinal cats with one hindlimb deafferented. J Neurosci 7:2537-2546.
Górska T, Bem T, Majczyński H, Zmyslowski W (1993) Unrestrained walking in intact cats. Brain Res Bull 32:235-240.

Grillner S, Zangger P (1979) On the central generation of locomotion in the low spinal cat. Exp Brain Res 34:241-261.

Helgren ME, Goldberger ME (1993) The recovery of postural reflexes and locomotion following low thoracic hemisection in adult cats involves compensation by undamaged primary afferent pathways. Exp Neurol 123:17-34.

Hodgson JA, Roy RR, de Leon R, Dobkin B, Edgerton VR (1994) Can the mammalian lumbar spinal cord learn a motor task? Med Sci Sports Exerc 26:1491-1497.

Howard CV and Reed M (2005) Estimation of component volume and volume fraction. In: Unbiased stereology: advanced methods, Ed 2 (Howard CV and Reed M, eds), pp 53-64. New York: Garland Science/BIOS Scientific Publishers.

Howland DR, Bregman BS, Tessler A, Goldberger ME (1995a) Transplants enhance locomotion in neonatal kittens whose spinal cords are transected: a behavioral and anatomical study. Exp Neurol 135:123-145.

Howland DR, Bregman BS, Tessler A, Goldberger ME (1995b) Development of locomotor behavior in the spinal kitten. Exp Neurol 135:108-122.

Jakeman LB, Hoschouer EL, Basso DM (2011) Injured mice at the gym: review, results and considerations for combining chondroitinase and locomotor exercise to enhance recovery after spinal cord injury. Brain Res Bull 84:317-326.

Karimi-Abdolrezaee S, Eftekharpour E, Wang J, Schut D, Fehlings MG (2010) Synergistic effects of transplanted adult neural stem/progenitor cells, chondroitinase, and growth factors promote functional repair and plasticity of the chronically injured spinal cord. J Neurosci 30:1657-1676.

Kato M, Murakami S, Yasuda K, Hirayama H (1984) Disruption of foreand hindlimb coordination during overground locomotion in cats with bilateral serial hemisection of the spinal cord. Neurosci Res 2:27-47.

Krajacic A, Weishaupt N, Girgis J, Tetzlaff W, Fouad K 2010 Traininginduced plasticity in rats with cervical spinal cord injury: effects and side effects. Behav Brain Res 214:323-331.

Kwok JC, Afshari F, García-Alías G, Fawcett JW (2008) Proteoglycans in the central nervous system: plasticity, regeneration and their stimulation with chondroitinase ABC. Restor Neurol Neurosci 26:131-145.

Lajoie K, Andujar JE, Pearson K, Drew T (2010) Neurons in area 5 of the posterior parietal cortex in the cat contribute to interlimb coordination during visually guided locomotion: a role in working memory. J Neurophysiol 103:2234-2254.

Lavoie S, Drew T (2002) Discharge characteristics of neurons in the red nucleus during voluntary gait modifications: a comparison with the motor cortex. J Neurophysiol 88:1791-1814.

Levin MF, Kleim JA, Wolf SL (2009) What do motor "recovery" and "compensation" mean in patients following stroke? Neurorehabil Neural Repair 23:313-319.

Liu YL, Guo YS, Xu L, Wu SY, Wu DX, Yang C, Zhang Y, Li CY (2009) Alternation of neurofilaments in immune-mediated injury of spinal cord motor neurons. Spinal Cord 47:166-170.

Lovely RG, Gregor RJ, Roy RR, Edgerton VR (1986) Effects of training on the recovery of full-weight-bearing stepping in the adult spinal cat. Exp Neurol 92:421-435.

Martin JE, Mather KS, Swash M, Garofalo O, Dale GE, Leigh PN, Anderton BH (1990) Spinal cord trauma in man: studies of phosphorylated neurofilament and ubiquitin expression. Brain 113:1553-1562.

Mewes K, Cheney PD (1994) Primate rubromotoneuronal cells: parametric relations and contribution to wrist movement. J Neurophysiol 72:14-30.

Miller S, Van Der Meché FG (1975) Movements of the forelimbs of the cat during stepping on a treadmill. Brain Res 91:255-269.

Miller S, van der Meché FG (1976) Coordinated stepping of all four limbs in the high spinal cat. Brain Res 109:395-398.

Miller S, Reitsma DJ, van der Meché FG (1973a) Functional organization of long ascending propriospinal pathways linking lumbo-sacral and cervical segments in the cat. Brain Res 62:169-188.

Miller S, van Berkum R, van der Burg J, van der Meché FG (1973b) Interlimb co-ordination in stepping in the cat. J Physiol 230:30P-31P.

Miller S, Van Der Burg J, Van Der Meché F (1975a) Coordination of movements of the hindlimbs and forelimbs in different forms of locomotion in normal and decerebrate cats. Brain Res 91:217-237. 
Miller S, Van Der Burg J, Van Der Meché F (1975b) Locomotion in the cat: basic programmes of movement. Brain Res 91:239-253.

Mori S, Matsui T, Kuze B, Asanome M, Nakajima K, Matsuyama K (1998) Cerebellar-induced locomotion: reticulospinal control of spinal rhythm generating mechanism in cats. Ann N Y Acad Sci 860:94-105.

Raineteau O, Schwab ME (2001) Plasticity of motor systems after incomplete spinal cord injury. Nat Rev Neurosci 2:263-273.

Rossignol S, Dubuc R (1994) Spinal pattern generation. Curr Opin Neurobiol 4:894-902.

Rossignol S, Chau C, Brustein E, Belanger M, Barbeau H, Drew T (1996) Locomotor capacities after complete and partial lesions of the spinal cord. Acta Neurobiol Exp (Wars) 56:449-463.

Rossignol S, Drew T, Brustein E, Jiang W (1999) Locomotor performance and adaptation after partial or complete spinal cord lesions in the cat. Prog Brain Res 123:349-365.

Rossignol S, Giroux N, Chau C, Marcoux J, Brustein E, Reader TA (2001) Pharmacological aids to locomotor training after spinal injury in the cat. J Physiol 533:65-74.

Rossignol S, Bouyer L, Barthélemy D, Langlet C, Leblond H (2002) Recovery of locomotion in the cat following spinal cord lesions. Brain Res Brain Res Rev 40:257-266.

Sandrow-Feinberg HR, Izzi J, Shumsky JS, Zhukareva V, Houle JD (2009) Forced exercise as a rehabilitation strategy after unilateral cervical spinal cord contusion injury. J Neurotrauma 26:721-731.

Schumacher PA, Eubanks JH, Fehlings MG (1999) Increased calpain I-mediated proteolysis, and preferential loss of dephosphorylated NF200, following traumatic spinal cord injury. Neuroscience 91:733-744.

Silver J, Miller JH (2004) Regeneration beyond the glial scar. Nat Rev Neurosci 5:146-156.

Stuart DC, Withey TP, Wetzel MC, Goslow GE Jr (1973) Time constraints for interlimb-limb co-ordination in the cat during unrestrained locomotion. In: Control of posture and locomotion (Stein RB, Pearson KG, Smith RS, Redfore JB, eds), pp 537-560. New York: Plenum.
Tester NJ, Howland DR (2008) Chondroitinase ABC improves basic and skilled locomotion in spinal cord injured cats. Exp Neurol 209:483-496.

Tester NJ, Plaas AH, Howland DR (2007) Effect of body temperature on chondroitinase ABC's ability to cleave chondroitin sulfate glycosaminoglycans. J Neurosci Res 85:1110-1118.

Thomas SL, Gorassini MA (2005) Increases in corticospinal tract function by treadmill training after incomplete spinal cord injury. J Neurophysiol 94:2844-2855.

Tom VJ, Sandrow-Feinberg HR, Miller K, Santi L, Connors T, Lemay MA, Houlé JD (2009) Combining peripheral nerve grafts and chondroitinase promotes functional axonal regeneration in the chronically injured spinal cord. J Neurosci 29:14881-14890.

von Euler M, Janson AM, Larsen JO, Seiger A, Forno L, Bunge MB, Sundström E (2002) Spontaneous axonal regeneration in rodent spinal cord after ischemic injury. J Neuropathol Exp Neurol 61:64-75.

Wessels M, Lucas C, Eriks I, de Groot S (2010) Body weight-supported gait training for restoration of walking in people with an incomplete spinal cord injury: a systematic review. J Rehabil Med 42:513-519.

Wetzel MC, Stuart DG (1976) Ensemble characteristics of cat locomotion and its neural control. Prog Neurobiol 7:1-98.

Wetzel MC, Atwater AE, Wait JV, Stuart DC (1975) Neural implications of different profiles between treadmill and overground locomotion timings in cats. J Neurophysiol 38:492-501.

Wetzel MC, Anderson RC, Brady Jr, RH, Norgren KS (1977) Kinematics of treadmill galloping by cats III. Coordination during Gait Conversions and Implications for Neural Control. Behav Biol 21:107-127.

Whelan PJ (1996) Control of locomotion in the decerebrate cat. Prog Neurobiol 49:481-515.

Widajewicz W, Kably B, Drew T (1994) Motor cortical activity during voluntary gait modifications in the cat. II. Cells related to the hindlimbs. J Neurophysiol 72:2070-2089.

Yick LW, So KF, Cheung PT, Wu WT (2004) Lithium chloride reinforces the regeneration-promoting effect of chondroitinase $\mathrm{ABC}$ on rubrospinal neurons after spinal cord injury. J Neurotrauma 21:932-943. 